\title{
SISTEM PAKAR DIAGNOSA DINI DEFISIENSI VITAMIN DAN MINERAL
}

\author{
Ause Labellapansa ${ }^{1}$, Alex Timur Boyz ${ }^{2}$ \\ Jurusan Teknik Informatika, Fakultas Teknik, Universitas Islam Riau ${ }^{1,2}$ \\ J1. Kaharudin Nasution no.113 Pekanbaru \\ Email: ause.labella@eng.uir.ac.id ${ }^{1}, \underline{\text { alex.tbz00@gmail.com² }}{ }^{2}$
}

\begin{abstract}
Abstrak
Mineral dan vitamin berperan penting bagi tubuh manusia. Vitamin berguna untuk proses pertumbuhan, pengaturan, dan perbaikan fungsi tubuh sedangkan mineral berperan dalam beberapa tahap reaksi metabolisme energi, pertumbuhan, dan pemeliharaan tubuh. Pentingnya peran vitamin dan mineral mengakibatkan perlunya dijaga kadar vitamin dan mineral didalam tubuh. Banyak yang tidak mengetahui bahwa gejala yang dirasakan pada tubuh merupakan akibat dari defisiensi suatu vitamin atau mineral tertentu sehingga seringkali terlambat untuk diketahui dan mengakibatkan perlunya kunjungan ke dokter. Defisiensi terhadap vitamin dan mineral dapat diketahui secara lebih dini dengan menggunakan bidang ilmu kecerdasan buatan melalui sistem pakar. Sistem pakar defisiensi vitamin dan mineral ini terdiri dari 11 vitamin dan 6 mineral. Dari akuisisi pengetahuan oleh seorang pakar, ditemukan 46 gejala dan menghasilkan 35 aturan (rule) yang direpresentasikan menggunakan tabel keputusan. Metode penelusuran defisiensi menggunakan forward chaining sedangkan untuk menangani ketidakpastian yang muncul digunakan metode certainty factor dari aplikasi Mycin. Untuk memudahkan pengguna, maka sistem dibuat dengan menggunakan teknologi mobile. Berdasarkan pengujian yang dilakukan kepada pakar dapat dibuktikan bahwa sistem pakar yang dibangun mampu mendiagnosa defisiensi vitamin dan mineral dengan nilai akurasi kebenaran sebesar 100\%. Dengan diketahuinya defisiensi yang terjadi maka penanganan dan pencegahan dapat dilakukan secara lebih dini.
\end{abstract}

Kata Kunci: Certainty Factor, Forward chaining, Vitamin dan Mineral

\section{PENDAHULUAN}

Vitamin dan mineral merupakan nutrisi atau zat yang sangat berperan penting bagi tubuh dan merupakan salah satu indikator penentu kesehatan pada tubuh manusia. Vitamin adalah suatu zat senyawa kompleks yang sangat dibutuhkan oleh tubuh yang sangat berperan penting untuk membantu pengaturan atau proses kegiatan pada tubuh manusia sedangkan mineral merupakan mikronutrien yang berfungsi untuk proses pertumbuhan, pengaturan, dan perbaikan fungsi tubuh [1].

Kekurangan atau defisiensi terhadap vitamin dan mineral dapat menjadi masalah bagi kesehatan manusia sehingga menimbulkan berbagai penyakit pada tubuh. Banyak yang tidak mengetahui bahwa gejala yang dirasakan pada tubuh merupakan akibat dari defisiensi suatu vitamin atau mineral tertentu sehingga seringkali terlambat untuk diketahui dan mengakibatkan perlunya kunjungan ke dokter.

Terdapat bidang ilmu kecerdasan buatan yang mampu membantu untuk mengetahui secara dini defisiensi vitamin dan mineral dan dapat pula membantu para profesional kedokteran dalam menentukan defisiensi vitamin dan mineral yaitu sistem pakar. Sistem pakar merupakan suatu program komputer yang dirancang untuk memodelkan kemampuan penyelesaian masalah yang dilakukan oleh seorang pakar [2]. Dengan dibangunnya sistem pakar, selain calon pasien, dokter muda atau dokter yang baru lulus serta dokter magang dapat melihat kondisi pasien tersebut berdasarkan gejala yang dimiliki apakah sesuai dengan analisa dari dokter spesialis. 
Sistem pakar yang dibangun menggunakan metode penelusuran maju (forward chaining) dan untuk menangani masalah ketidakpastian yang muncul digunakan metode Certainty Factor. Pengetahuan disajikan dalam bentuk pohon keputusan. Teknologi yang digunakan berbasis mobile dengan perangkat android dan aplikasi dalam bentuk Android Aplication. Adapun jenis kekurangan vitamin yang terdapat dalam sistem pakar ini terdiri dari vitamin A, B (B1, B2, B3, B5, B6, B12), C, D, E dan vitamin K sedangkan jenis jenis mineralnya terdiri dari mineral Makro $(\operatorname{Kalsium}(\mathrm{Ca})$, $\operatorname{Fosfor}(P)$, Magnesium $(M g)$ ) dan Mineral Mikro (Seng $(Z n)$, Besi $(F e)$, Tembaga $(C u)$ ).

\section{TINJAUAN PUSTAKA}

Beberapa penelitian terdahulu telah dilakukan baik untuk melakukan deteksi dini defisiensi vitamin dan mineral maupun penelitian dari kesamaan metode yang digunakan. Dalam penelitiannya, Syatibi [3] membangun sistem pakar diagnosa penyakit kulit sapi berbasis web dengan menggunakan metode certainty factor. Langkah-langkah dalam penelitiannya diantaranya adalah metode pengumpulan data baik data yang diperoleh dari studi pustaka maupun dari akusisi pengetahuan dari pakar melalui wawancara, kemudian melakukan representasi pengetahuan dari data yang sudah didapat untuk dijadikan knowledge base pada sistem pakar. Metode ketidakpastian yang digunakan adalah metode certainty factor yang digunakan untuk menghitung atau mengolah setiap gejala berdasarkan bobot yang telah didapatkan dari observasi. Dari hasil pengujian sistem, dikatakan bahwa pemanfaatan metode certainty factor pada sistem tersebut telah memberikan hasil yang baik sehingga menghasilkan aplikasi sistem pakar yang dapat digunakan untuk membantu mendiagnosa penyakit kulit pada sapi berdasarkan gejala-gejala fisik yang dimiliki oleh sapi.

Penelitian Latumakulita [4] membangun sistem pakar mendiagnosa penyakit pada anak dengan menggunakan metode ketidakpastian certainty factor. Adapun langkahlangkah dalam penelitian tersebut adalah metode pengumpulan data baik data yang diperoleh dari studi pustaka maupun dari akusisi pengetahuan dari pakar melalui wawancara, dimana gejala-gejala yang dialami pada penyakit anak akan diberikan tingkat kepercayaan oleh pakar kemudian dilakukan representasi pengetahuan dari data yang sudah didapat untuk dijadikan knowledge base sistem pakar dan diterapkan melalui program berbasis desktop.

Sari [5] mempertegas dalam jurnalnya dengan membangunn sistem pakar mendiagnosa penyakit demam berdarah menggunakan metode certainty factor. Dalam penelitiannya, dikatakan bahwa penerapan metode certainty factor dapat mempermudah dalam memberikan perhitungan penyelesaian terhadap gejala-gejala yang dialami oleh user dan seberapa pasti tingkat kepastian para user atau pasien menderita penyakit demam berdarah. Sari [5] melakukan penelitian dengan mewawancarai pakar atau ahli dibidang kesehatan untuk mendapatkan data mengenai gejala penyakit demam berdarah kemudian dari gejala-gejala tersebut diberikan pembobotan dengan metode certainty factor bedasarkan tingkat kepercayaan pakar terhadap gejala-gejala yang menyebabkan terjadinya demam dan data yang sudah dikumpulkan digunakan sebagai knowledge base pada sistem pakar untuk mendiagnosa penyakit demam berdarah.

\section{METODE PENELITIAN}

Pada penelitian ini dibagi kedalam beberapa tahapan yang digunakan untuk membangun aplikasi sistem pakar, dimulai dari tahapan identifikasi masalah atau analisa, akusisi pengetahuan dan representasi pengetahuan. Pada penelitian ini juga digunakan metode certainty factor untuk menangani masalah ketidakpastian terhadap hasil pada aplikasi sistem pakar. 


\subsection{Identifikasi Masalah dan Pengetahuan}

Pembuatan sistem pakar ini diawali dengan menentukan masalah, dalam hal ini adalah menentukan kekurangan atau defisiensi vitamin dan mineral pada tubuh. Hal ini sangat penting dilakukan untuk menentukan pengetahuan yang selanjutnya akan diperlukan dalam sistem. Proses identifikasi pengetahuan diawali dari akusisi pengetahuan dan dilanjutkan dengan representasi pengetahuan.

\subsection{Akusisi Pengetahuan}

Akusisi pengetahuan merupakan suatu proses untuk mengumpulkan data-data pengetahuan akan suatu masalah. Pada penelitian ini digunakan dua jenis data yang diperoleh melalui cara yang berbeda. Jenis data yang digunakan adalah data primer yang diambil langsung melalui narasumber dalam hal ini pakar yaitu orang di jadikan obyek penelitian untuk mendapat informasi maupun data. Pencarian data primer pada penelitian ini nantinya akan dilakukan dengan cara mewawancari seorang pakar yang merupakan salah seorang dokter yang saat ini bekerja di salah satu Rumah Sakit di Pekanbaru. Dalam penelitian ini juga didapatkan informasi dari buku-buku kesehatan yang ada di perpustakaan, jurnal penelitian serta literatur-literatur lain yang mendukung penelitian ini.

\subsection{Representasi Pengetahuan}

Setelah proses pengumpulan data selesai dilakukan, maka dilakukan representasi data kedalam basis pengetahuan dan basis aturan yang kemudian dikodekan, diorganisasikan dan digambarkan dalam bentuk rancangan lain sehingga menjadi bentuk yang sistematis. Adapun representasi pengetahuan yang dilakukan kedalam sistem pakar diagnosa defisensi vitamin dan mineral ini adalah dengan menggunakan tabel keputusan dan kemudian dibentuk suatu kaidah produksi.

\section{HASIL DAN PEMBAHASAN}

Tabel 1 merupakan tabel keputusan defisiensi vitamin dan mineral yang berisi hubungan antar gejala dan penyakit. Dari tabel keputusan inilah dibuat aturan (rule) untuk sistem pakar ini. Jumlah penyakit terdiri dari 17 penyakit dan gejala sebanyak 46 gejala. Adapun Tabel 1 merupakan penjelasan dari ke 45 macam gejal defisiensi. Dari gejala yang dirasakan, maka dapat diketahui defisiensi yang dimiliki seseorang beserta dengan solusi untuk menangani masalah defisiensi tersebut.

Tabel 1. Tabel keputusan Defisiensi Vitamin dan Mineral

\begin{tabular}{|c|c|c|c|c|c|c|c|c|c|c|c|c|c|c|c|c|c|c|c|c|c|c|c|c|}
\hline \multirow{2}{*}{$\begin{array}{c}\text { Aturan } \\
\mathrm{Ke}:\end{array}$} & \multicolumn{22}{|c|}{ Id Gejala } & \multirow{2}{*}{$\begin{array}{c}\text { Id } \\
\text { penyakit }\end{array}$} & \multirow{2}{*}{$\begin{array}{c}\text { Nilai } \\
\text { of pakar }\end{array}$} \\
\hline & G1 & G2 & G3 & G4 & G5 & G6 & G7 & G8 & G9 & G10 & G11 & G12 & G13 & G14 & G15 & G16 & G17 & G18 & G19 & G20 & G21 & G22 & & \\
\hline 1 & $\mathrm{x}$ & & & $x$ & $x$ & & & & & & & & & & & & & & & & & & P1 & 0.8 \\
\hline 2 & & $x$ & & $x$ & $x$ & & & & & & & & & & & & & & & & & & P1 & 0.8 \\
\hline 3 & & & $x$ & $x$ & $x$ & & & & & & & & & & & & & & & & & & Pl & 1 \\
\hline 4 & & & & & & $x$ & & & $x$ & $x$ & & & & & & & & & & & & & P2 & 1 \\
\hline 5 & & & & & & & $x$ & & $x$ & $x$ & & & & & & & & & & & & & P2 & 0.8 \\
\hline 6 & & & & & & & & $\mathrm{x}$ & $x$ & $x$ & & & & & & & & & & & & & P2 & 0.6 \\
\hline 7 & & & & & & & & & & & $x$ & & $\mathrm{x}$ & $x$ & & & & & & & & & P3 & 0.8 \\
\hline 8 & & & & & & & & & & & & $x$ & $x$ & $x$ & & & & & & & & & P3 & 0.6 \\
\hline 9 & & & & & & & & & & & & & & & $x$ & & & $x$ & & & & & P4 & 1 \\
\hline 10 & & & & & & & & & & & & & & & $x$ & $x$ & & & & & & & P4 & 0.8 \\
\hline 11 & & & & & & & & & & & & & & & $x$ & & $x$ & & & & & & P4 & 0.8 \\
\hline 12 & & & & & & & & & & & & & & & & $x$ & & & $x$ & & & & P5 & 0.6 \\
\hline 13 & & & & & & & & $x$ & & & & & & & & & & & $x$ & & & & P5 & 1 \\
\hline 14 & & & & & & & & $x$ & & & & & & & & & & & & $x$ & & & P6 & 0.8 \\
\hline 15 & & & & & & $x$ & & & & & & & & & & & & & & & $x$ & $x$ & P7 & 0.8 \\
\hline 16 & & & & & & & $x$ & & & & & & & & & & & & & & $x$ & $x$ & P7 & 0.6 \\
\hline
\end{tabular}




\begin{tabular}{|c|c|c|c|c|c|c|c|c|c|c|c|c|c|c|c|c|c|c|c|c|c|c|}
\hline \multirow{2}{*}{$\begin{array}{c}\text { Aturan } \\
\mathrm{Ke}:\end{array}$} & \multicolumn{20}{|c|}{ Id gejala } & \multirow{2}{*}{$\begin{array}{c}\text { Id } \\
\text { penyakit }\end{array}$} & \multirow{2}{*}{$\begin{array}{c}\text { Nilai } \\
\text { ef pakar }\end{array}$} \\
\hline & \begin{tabular}{|l} 
G6 \\
\end{tabular} & G8 & G21 & G22 & G23 & G24 & G25 & G26 & G27 & G28 & G29 & G30 & G31 & G32 & G33 & G34 & G35 & G36 & G37 & G38 & & \\
\hline 17 & & & & & $x$ & $x$ & $x$ & & & & & & & & & & & & & & P8 & 1 \\
\hline 18 & & & & & & & & $\mathrm{x}$ & $\mathrm{x}$ & & & & & & & & & & & & P9 & 0.8 \\
\hline 19 & & & & & & & & $x$ & & $x$ & & & & & & & & & & & P9 & 1 \\
\hline 20 & & & & & & & & & & & $\mathrm{x}$ & $x$ & & & & & & & & & P10 & 0.8 \\
\hline 21 & & & & & & & & & & & $x$ & & $\mathrm{x}$ & & & & & & & & P10 & 0.8 \\
\hline 22 & & & & & & & & & & & & & & $\mathrm{x}$ & $x$ & $\mathrm{x}$ & & & & & P11 & 1 \\
\hline 23 & & & $\mathrm{x}$ & & & & & & & & & & & $\mathrm{x}$ & $\mathrm{x}$ & & & & & & P11 & 0.6 \\
\hline 24 & & & & & & & & & & & & & & & & & $x$ & $x$ & & & P12 & 0.8 \\
\hline 25 & & & & & & & & & & & & & & & & $\mathrm{x}$ & $\mathrm{x}$ & & & & $\mathrm{P} 12$ & 0.4 \\
\hline 26 & & $x$ & & & & & & & & & & & & & & & $x$ & & & & P12 & 0.8 \\
\hline 27 & & & & & & & & & & & & & & & & & & & $\mathrm{x}$ & $\mathrm{x}$ & P13 & 0.8 \\
\hline 28 & $x$ & & & & & & & & & & & & & & & & & & $x$ & & P13 & 0.4 \\
\hline
\end{tabular}

\begin{tabular}{|c|c|c|c|c|c|c|c|c|c|c|c|c|c|c|c|c|}
\hline \multirow{2}{*}{$\begin{array}{c}\text { Aturan } \\
\mathbf{K e}:\end{array}$} & \multicolumn{14}{|c|}{ Id gejala } & \multirow{2}{*}{$\begin{array}{c}\text { Id } \\
\text { penyakit }\end{array}$} & \multirow{2}{*}{$\begin{array}{c}\text { Nilai } \\
\text { ff pakar }\end{array}$} \\
\hline & G6 & G15 & Gl6 & G17 & G22 & G26 & G39 & G40 & G41 & G42 & G43 & G44 & G45 & G46 & & \\
\hline 29 & $x$ & & & & & & $\mathrm{x}$ & $\mathrm{x}$ & & & & & & & P14 & 0.8 \\
\hline 30 & & & $x$ & & & & $\mathrm{x}$ & $x$ & & & & & & & P14 & 1 \\
\hline 31 & & & & & $x$ & & & & $x$ & $x$ & & & & & P15 & 0.8 \\
\hline 32 & & & & & & & & & & & $x$ & $x$ & & & P16 & 0.6 \\
\hline 33 & & & & & & $x$ & & & & & & $x$ & & & P16 & 0.8 \\
\hline 34 & & & & & & & & & & & & $x$ & $x$ & $x$ & P17 & 0.8 \\
\hline 35 & & & & & $x$ & & & & & & & & $x$ & $x$ & P17 & 1 \\
\hline
\end{tabular}

Tabel 2. Daftar Nama Gejala Defisiensi Vitamin dan Mineral

\begin{tabular}{|c|c|l|c|c|l|}
\hline NO & $\begin{array}{c}\text { Id } \\
\text { Gejala }\end{array}$ & \multicolumn{1}{|c|}{ Nama Gejala } & NO & $\begin{array}{c}\text { Id } \\
\text { Gejala }\end{array}$ & \multicolumn{1}{|c|}{ Nama Gejala } \\
\hline 1 & G1 & $\begin{array}{l}\text { Pertumbuhan tubuh tidak } \\
\text { sempurna }\end{array}$ & 24 & G24 & $\begin{array}{l}\text { Nyeri pada tulang pinggul dan } \\
\text { tulang punggung }\end{array}$ \\
\hline 2 & G2 & Timbul jerawat & 25 & G25 & Pembengkakan pada gusi \\
\hline 3 & G3 & $\begin{array}{l}\text { Terdapat bercak bitot ( bercak } \\
\text { putih seperti busa pada lapisan } \\
\text { kornea mata bagian luar) }\end{array}$ & 26 & G26 & Luka lambat sembuh \\
\hline 4 & G4 & Mengalami buta senja & 27 & G27 & Penurunan hasrat sesksual \\
\hline 5 & G5 & Mata terasa gatal dan terbakar & 28 & G28 & Rambut rontok \\
\hline 6 & G6 & Nafsu makan berkurang & 29 & G29 & Terjadi pendarahan pada hidung \\
\hline 7 & G7 & $\begin{array}{l}\text { Pencernaan sering terganggu } \\
\text { buang air belebihan }\end{array}$ & 30 & G30 & Tubuh mudah memar \\
\hline 8 & G8 & Insomnia atau sulit tidur & 31 & G31 & $\begin{array}{l}\text { Pada wanita menstruasi mengalir } \\
\text { deras }\end{array}$ \\
\hline 9 & G9 & Irama detak jantung cepat & 32 & G32 & Terjadi pendarahan pada gusi \\
\hline 10 & G10 & Kulit pada sekitar tangan bersisik & 33 & G33 & Sariawan \\
\hline 11 & G11 & Mulut terasa kering & 34 & G34 & Sesak nafas \\
\hline 12 & G12 & $\begin{array}{l}\text { Terdapat keretakan pada sudut } \\
\text { mulut }\end{array}$ & 35 & G35 & Keringat berlebihan \\
\hline 13 & G13 & Iritasi kulit/kulit memerah & 36 & G36 & Sembelit atau susah buang air besat \\
\hline
\end{tabular}




\begin{tabular}{|c|c|c|c|c|c|}
\hline 14 & G14 & $\begin{array}{l}\text { Daya tahan tubuh berkurang } \\
\text { ditandai dengan flu parah }\end{array}$ & 37 & G37 & Otot terasa sangat lemah \\
\hline 15 & G15 & Sering muntah atau mual & 38 & G38 & Tubuh terasa lesu dan cepat lelah \\
\hline 16 & G16 & Otot sering kram & 39 & G39 & $\begin{array}{l}\text { Fibromyalgia (bagian tubuh } \\
\text { tertentu sensitif bila disentuh } \\
\text { biasanya pada leher dan panggul) }\end{array}$ \\
\hline 17 & G17 & Terasa sering pegal pada mulut & 40 & G40 & Sakit kepala sebelah/migrain \\
\hline 18 & G18 & $\begin{array}{l}\text { Kulit sensitif bila terkena sinar } \\
\text { matahari }\end{array}$ & 41 & G41 & Konsentrasi berkurang \\
\hline 19 & G19 & $\begin{array}{lll}\begin{array}{l}\text { Mengalami } \\
\text { kepala }\end{array} & & \\
\end{array}$ & 42 & G42 & $\begin{array}{l}\text { Kuku tampak tipis dan berbentuk } \\
\text { cekung / kuku sendok }\end{array}$ \\
\hline 20 & G20 & $\begin{array}{l}\text { Delaga ( kulit pada bagian tumit } \\
\text { pecah-pecah) }\end{array}$ & 43 & G43 & Mengalami demam tinggi \\
\hline 21 & G21 & Lengan dan kaki terasa lemah & 44 & G44 & Pertumbuhan lambat \\
\hline 22 & G22 & $\begin{array}{l}\text { Anemia yang ditandai dengan } \\
\text { wajah pucat }\end{array}$ & 45 & G45 & $\begin{array}{l}\text { Demineralisasi tulang (sakit dan } \\
\text { nyeri yang parah pada bagian } \\
\text { pinggang) }\end{array}$ \\
\hline 23 & $\mathrm{G} 23$ & $\begin{array}{l}\text { Rasa terbakar yang terjadi pada } \\
\text { mulut dan tenggorokan }\end{array}$ & 46 & G46 & $\begin{array}{l}\text { Depigmentase (perubahan warna } \\
\text { rambut dan kulit) }\end{array}$ \\
\hline
\end{tabular}

Tabel 3 Daftar Nama Penyakit Defisiensi Vitamin dan Mineral

\begin{tabular}{|c|c|l|}
\hline NO & Id Penyakit & \multicolumn{1}{|c|}{ Nama Penyakit } \\
\hline 1 & P1 & Defisisiensi Vitamin A \\
\hline 2 & P2 & Defisisiensi Vitamin B1 \\
\hline 3 & P3 & Defisisiensi Vitamin B2 \\
\hline 4 & P4 & Defisisiensi Vitamin B3 \\
\hline 5 & P5 & Defisisiensi Vitamin B5 \\
\hline 6 & P6 & Defisisiensi Vitamin B6 \\
\hline 7 & P7 & Defisisiensi Vitamin B12 \\
\hline 8 & P8 & Defisisiensi Vitamin C \\
\hline 9 & P9 & Defisisiensi Vitamin D \\
\hline 10 & P10 & Defisisiensi Vitamin E \\
\hline 11 & P11 & Defisisiensi Vitamin K \\
\hline 12 & P12 & Kalsium \\
\hline 13 & P13 & Fosfor \\
\hline 14 & P14 & Magnesium \\
\hline 15 & P15 & Defisiensi Mineral Seng / Zink (Zn) \\
\hline 16 & P16 & Defisiensi Mineral Besi / Ferrum (Fe) \\
\hline 17 & P17 & $\begin{array}{l}\text { Defisiensi Mineral Tembaga / Cupprum } \\
\text { (Cu) }\end{array}$ \\
\hline
\end{tabular}




\subsection{Penanganan Ketidakpastian}

Pada penelitian ini di gunakan metode certainty factor (CF) untuk penanganan ketidakpastian terhadap sistem pakar. Nilai $\mathrm{CF}$ akan berada dalam range 1 sampai dengan -1 dimana nilai 1 menyatakan kepercayaan mutlak dan nilai -1 menyatakan ketidakpercayaan mutlak. Pada MYCIN juga digunakan konsep threshold dimana digunakan level threshold yaitu 0,2 yang dinotasikan dengan $\delta$ (delta). Persamaan (1) digunakan untuk menentukan premis CF suatu rule [6].

$$
\begin{gathered}
R I_{k}(c f)=\left\{\begin{array}{ccc}
\min \{\operatorname{Pi}(c f)\}, & \text { jika } P_{i}(c f) \geq \delta \\
\max \{P i(c f)\}, & \text { jika } P_{i}(c f) \leq-\delta \\
0, \text { jika }\left|P_{i}(c f)\right|<\delta \text { for any } i \\
0, & \text { jika } \operatorname{Pi}(c f) \text { berlawanan tanda }
\end{array}\right. \\
\text { Dengan: } \\
\begin{array}{rll}
R I_{k}(c f) & = & \text { CF komposit premis aturan k } \\
P i(c f) & = & \text { CF Premis klausa i } \\
\delta & = & \text { Level threshold CF }
\end{array}
\end{gathered}
$$

Selanjutnya Ignizio [6] menghitung CF output rule dengan menggunakan persamaan (2)

dimana

$$
c f_{k}=R I_{k}(c f) \cdot\left[R_{k}(c f)\right]
$$

$$
\begin{array}{lll}
c f_{k} & = & \mathrm{CF} \text { output aturan } \mathrm{k} \\
R_{k}(c f) & = & \mathrm{CF} \text { aturan } \mathrm{k} \\
R I_{k}(c f) & = & \mathrm{CF} \text { komposit premis aturan } \mathrm{k}
\end{array}
$$

Jika diperoleh lebih dari 1 kesimpulan untuk satu penyakit maka dilakukan perhitungan $\mathrm{CF}$ gabungan dengan menggunakan persamaan (3)

$$
\begin{aligned}
& \begin{array}{l}
C(c f) \\
=\left\{\begin{array}{c}
c f_{1}+c f_{2}-\left(c f_{1} \cdot c f_{2}\right), \text { jika } c f_{1} \text { dan } c f_{2} \geq 0 \\
\frac{c f_{1}+c f_{2}}{1-\min \left(\left|c f_{1}\right|,\left|c f_{2}\right|\right.}, \text { jika salah satu } c f_{1} \text { atau } c f_{2}<0 \\
c f_{1}+c f_{2}+c f_{1} \cdot c f_{2}, \text { jika } c f_{1} \text { dan } c f_{2}<0
\end{array}\right.
\end{array} \\
& \text { dimana } \\
& \begin{array}{lll}
C(c f) & = & \text { Kesimpulan CF C } \\
c f_{1} & = & \text { CF aturan 1 } \\
c f_{2} & = & \text { CF aturan 2 }
\end{array}
\end{aligned}
$$

Pada sistem pakar ini, nilai factor kepastian diperoleh dari CF pengguna dan CF pakar. Nilai CF pengguna diperoleh saat melakukan diagnosa terhadap suatu gejala sedangkan nilai CF pakar diberikan terhadap suatu penyakit dalam sebuah rule (aturan) dengan menggunakan operator AND pada setiap aturan yang dibuat.

Diberikan contoh perhitungan menggunakan CF yang jawabannya diperoleh dari pilihan check box yang di tampilkan oleh sistem kepada pengguna, pengguna memberikan checklist atau mencentang check box pada gejala G4 (Buta Senja) dengan nilai $\mathrm{Cf}$ user atau tingkat keyakinan pengguna yaitu 1 (pasti), gejala G5 (mata gatal dan terbakar) dengan nilai $\mathrm{Cf}$ user atau tingkat keyakinan pengguna yaitu 1 (pasti), G1 (Mulut Terasa Kering) dan G2 (Timbul Jerawat) dengan nilai Cf user atau tingkat keyakinan pengguna yaitu 0.8 . Tabel 4 merupakan contoh gejala beserta tingkat kepercayaan user terhadap gejala yang dialami : 
Tabel 4 Tabel Gejala dan Nilai CF User

\begin{tabular}{|c|c|}
\hline Kode Gejala & Nilai Cf User \\
\hline G4 & 1 \\
\hline G5 & 1 \\
\hline G3 & 0.8 \\
\hline G1 & 0.8 \\
\hline
\end{tabular}

Berdasarkan jawaban user tersebut, diperoleh kaidah-kaidah yang terpenuhi yaitu:

\section{Kaidah 1}

IF G4 [ Cf User $=1]$

AND G5 [ Cf User $=1]$

AND G1 [ Cf User $=0.8]$

THEN Defisiensi Vitamin A

( Cf Pakar $=0.8$ )
Kaidah 3

IF G4 [ Cf User $=1]$

AND G5 [ Cf User $=1]$

AND G3 [ Cf User $=0.8]$

THEN Defisiensi Vitamin A

( Cf Pakar =1)

Adapun seluruh nilai CF aturan yang muncul diselesaikan dengan menggunakan persamaan (2) yaitu :

\section{Untuk Aturan 1}

CF Komposit Premis Rule $1(1 ; 1 ; 0,8) \quad=\quad$ Min $(1 ; 1 ; 0,8)=0.8$

$\mathrm{CF}(\mathrm{R} 1) \quad=\mathrm{CF}$ komposit Premis R1 * Cf $($ Pakar $)$

$=0.8 * 0.8$

Untuk Aturan 3

$=0,64$

CF Komposit Premis Rule $3(1 ; 1 ; 0.8)=\operatorname{Min}(1 ; 1 ; 0.8)=0.8$

$\mathrm{CF}(\mathrm{R} 3) \quad=\mathrm{CF}$ komposit Premis R2 * Cf $($ Pakar $)$

$=0.8 * 1$

$=0,8$

Kesimpulan penyakit Defisiensi vitamin A memiliki lebih dari 1 aturan yaitu aturan 1 dan aturan 3 dengan nilai CF lebih besar dari nol, maka dilakukan perhitungan untuk menemukan CF kesimpulan dengan menggunakan persamaan (3) yaitu :

$$
\begin{aligned}
\text { Conclusion }(\mathrm{Cf})= & \mathbf{0 , 6 4}+(\mathbf{0 , 8}-(\mathbf{0 , 6 4} * \mathbf{0 , 8})) \\
= & \mathbf{0 , 9 2 8 .}
\end{aligned}
$$

CF kesimpulan yaitu pasien terdiagnosa penyakit Defisiensi vitamin A dengan tingkat keyakinan $\mathbf{0 , 9 2 8}$ atau $\mathbf{9 2 , 8 \%}$. Sistem kemudian akan memberikan penjelasan mulai dari gejala yang dimiliki, hasil defisiensi, tingkat keyakinan serta solusi sesuai dengan defisiensi vitamin yang dimiliki.

\subsection{Pengujian Sistem berbasis Rule/Aturan Diagnosa Dengan Pakar}

Pengujian sistem pakar dilakukan dengan menggunakan black box dan dengan melalui pengujian oleh pakar secara langsung. Berdasarkan hasil pengujian dari pakar, diperoleh kesimpulan bahwa baik hasil diagnosa dari pakar maupun hasil diagnosa dari sistem memberikan kesimpulan yang sama.

\section{KESIMPULAN}

Adapun kesimpulan pada penelitian ini yaitu:

1. Pada penelitian ini telah berhasil dibuat sistem dengan menggunakan metode perhitungan certainty factor (CF) untuk mengatasi faktor ketidakpastian yang dapat membantu diagnosa defisiensi vitamin dan mineral pada tubuh manusia.

2. Berdasarkan hasil pengujian terhadap perhitungan certainty factor (CF) secara manual dan hasil perhitungan yang dilakukan oleh sistem didapatkan hasil yang 
sama dalam menentukan tingkat kepercayaan akhir (CF conclusion) terhadap suatu diagnosa.

3. Hasil pengujian validasi dan fungsionalitas yang dimiliki oleh sistem menunjukan bahwa sistem memiliki fungsionalitas sebesar $100 \%$ dan dari berdasarkan pengujian yang dilakukan oleh pakar kepada sistem diperoleh hasil bahwa baik hasil diagnosa dari pakar maupun hasil diagnosa dari sistem memberikan kesimpulan hasil diagnosa yang sama.

\section{DAFTAR PUSTAKA}

[1] Almatsier, Sunita, Prinsip Dasar Ilmu Gizi, Gramedia Pustaka utama, Jakarta, 2011

[2] Sutojo, Edi Mulyanto., Kecerdasan Buatan, Andi Offset, Yogyakarta, 2011.

[3] Syatibi, Ahmad, Sistem Pakar Diagnosa Awal Penyakit Kulit Sapi Berbasis Web Dengan Menggunakan Metode Certainty Factor, Thesis, Universitas Diponegoro, Semarang, 2012.

[4] Latumakulita, Luther A., Jurnal Ilmiah Sains, Sistem Pakar Pendiagnosa Penyakit Anak Menggunakan Certainty Factor (CF), Vol 12 : 122-126,2012.

[5] Sari, Nur Anjas, Jurnal Pelita Informatika Budi Darma, Sistem Pakar Mendiagnosa Penyakit Demam Berdarah Menggunakan Metode Certainty Factor, Vol 3 : 100103, 2013.

[6] Ignizio, P. J., Intorduction to Expert Systems: The Develpoment and Implementation of Rule-Based Expert Systems, Mc Graw-Hill, Inc., United States of America, 1991 